\title{
DEVELOPMENT OF TECHNOLOGY OF COMBINED JOINING OF POSITION BUTTS OF THICK-WALLED PIPES OF HIGH-STRENGTH STEELS
}

\author{
S.I. KUCHUK-YATSENKO, B.I. KAZYMOV, V.F. ZAGADARCHUK and A.V. DIDKOVSKY \\ E.O. Paton Electric Welding Institute, NASU \\ 11 Bozhenko Str., 03680, Kiev, Ukraine. E-mail: office@paton.kiev.ua
}

\begin{abstract}
The modern pipeline systems are designed for high operating pressures. During construction of such systems the pipes with wall thickness of up to $40 \mathrm{~mm}$ are applied. For joining of such pipes the new more effective methods are developed, including the combined ones. The combined technology envisages the welding of root and filling welds using different methods. To increase the rates of construction and quality of welding it is offered to weld the root using flash-butt welding (FBW), and the filling layers must be produced using automatic electric arc welding. The aim of this work is to study the features of formation of joints produced using FBW of root welds in pipes with thickness of more than $20 \mathrm{~mm}$ with different edge preparation and to investigate the quality of joints of root welds and combined joints. The influence of edge groove on the welding process and formation of joints under the conditions of increased heat removal from welding zone during flashing was investigated. The technology of FBW of root welds of the position butts of thick-walled pipes of high-strength steels, combined with electric arc welding, was developed. The optimum FBW parameters at different thickness of projections of root weld groove were determined. The level of influence of electric arc welding on the properties of root welds was established, including the improvement of ductile properties of welded joints. The comprehensive mechanical tests of joints of root welds produced using FBW and the combined arc-welded joints were carried out indicating their practical equal strength with the base metal. Such a combined process will allow a great simplification and acceleration of the process of assembly and welding of the root weld, which predetermines the productivity of the whole process of the position butt welding. This ensures the high reliability and quality of root welds of the joint. 14 Ref., 8 Figures.
\end{abstract}

Keywords: flash-butt welding, electric arc welding, thick-walled pipes, edge preparatinon, position butts, root weld, combined joint, technological gap, heat removal, welding parameters, temperature distribution, mechanical tests

In the modern power systems, including gas transporting ones, designed for high pressures, the pipelines are widely used, which are constructed of thick-walled pipes of high-strength steels [1, 2]. The joining of such pipes represents a labor-consuming and responsible operation, which is carried out in the field conditions, usually using electric arc welding (EAW) by highlyskilled specialists. For EAW technologies a special preparation of pipe ends before welding is required, i.e. preparation of edge groove, the geometric shape and sizes of which largely affect the quality and mechanical properties of the joints (Figure 1) [1, 3].

The most difficult and responsible technological operation in EAW of pipes is welding of a root weld. The experience of using position butt welding of different pipelines proves that the majority of defects, detected in them during non- destructive testing, occur in the root welds. Very promising for position butt welding of thickwalled pipes are the complexes of orbital EAW in the environment of shielding gas of the CRCEvans AW company. The distinguishing feature of this technology is the strict requirements to geometric parameters of groove and assembly of pipes before welding, providing the required size of gaps in welding. At the same time, the first technological operation, i.e. welding of root weld, is performed in a separate equipment using welding consumables, different from those used for filling the edge groove. The sizes of a root part of a groove are controlled by the reference and should be in the range of tenth fractions of a millimeter. At the same time, it is not always possible to achieve the same high standards by the level of assembly of heavy and large-sized pipes before welding with the absence of inadmissible gaps and displacements between them when assembling in the field conditions.

The many-year experience in application of flash-butt welding (FBW) of different pipelines 
of 114-1,420 $\mathrm{mm}$ diameter with wall thickness of $5-20 \mathrm{~mm}$ proves a high service reliability of welded joints of pipes produced by FBW in different climatic conditions, including those of the Far North regions, during the construction of different pipelines $[4,5]$. In the recent decades about $50,000 \mathrm{~km}$ of pipelines were welded using this method, which are successfully operating at the moment. The industry mastered the production of equipment for FBW of pipes, in particular, welding machines K584 for the pipes of 114$325 \mathrm{~mm}$ diameter with wall thickness of 5$14 \mathrm{~mm}$, as well as machines of K830 and K700 types for pipes of 1220 and $1420 \mathrm{~mm}$ diameter and wall thickness of $12.7-20 \mathrm{~mm}$.

For welding of pipes with a larger wall thickness (more than $20 \mathrm{~mm}$ ) a new generation of welding machines is required, which is first of all connected with increase in their set power capacity and upsetting force. The designs of such machines were developed at the E.O. Paton Electric Welding Institute. For their realization the appropriate orders and the potential volumes of production are required.

At the same time, considering the existing park of machines for FBW of pipes, it is advisable to use them for realization of the combined welding technology that combines two technological processes: welding of root weld by FBW and the further filling of the remaining edge groove by EAW [6]. This method allows a considerable simplification and acceleration of the process of assembly and welding of the root weld, which predetermines the productivity of welding works for position pipe butts. Moreover, the high reliability and quality of root welds and the whole combined joint is provided. To produce the root welds of thick-walled pipes the whole existing park of the machines for FBW can be used without their significant reconstruction.

For FBW of root weld it is necessary to prepare a special groove (see Figure 1, b) at the ends of pipes with the factory (standard) edge groove (Figure 1, a). The factory (standard) groove at the ends of pipes delivered to the route can be remade in the field conditions for different EAW methods [3] in order to save welding consumables. The parameters of edge groove depend on the wall thickness of pipes and welding method of both root, as well as filling layers of arc welds. When preparing the edge groove most specialists try to reduce the volume of removable metal of pipes. For comparison, Figure 1, $c$ shows a scheme for edge preparation of as-assembled pipes for welding by the CRC-Evans AW method.
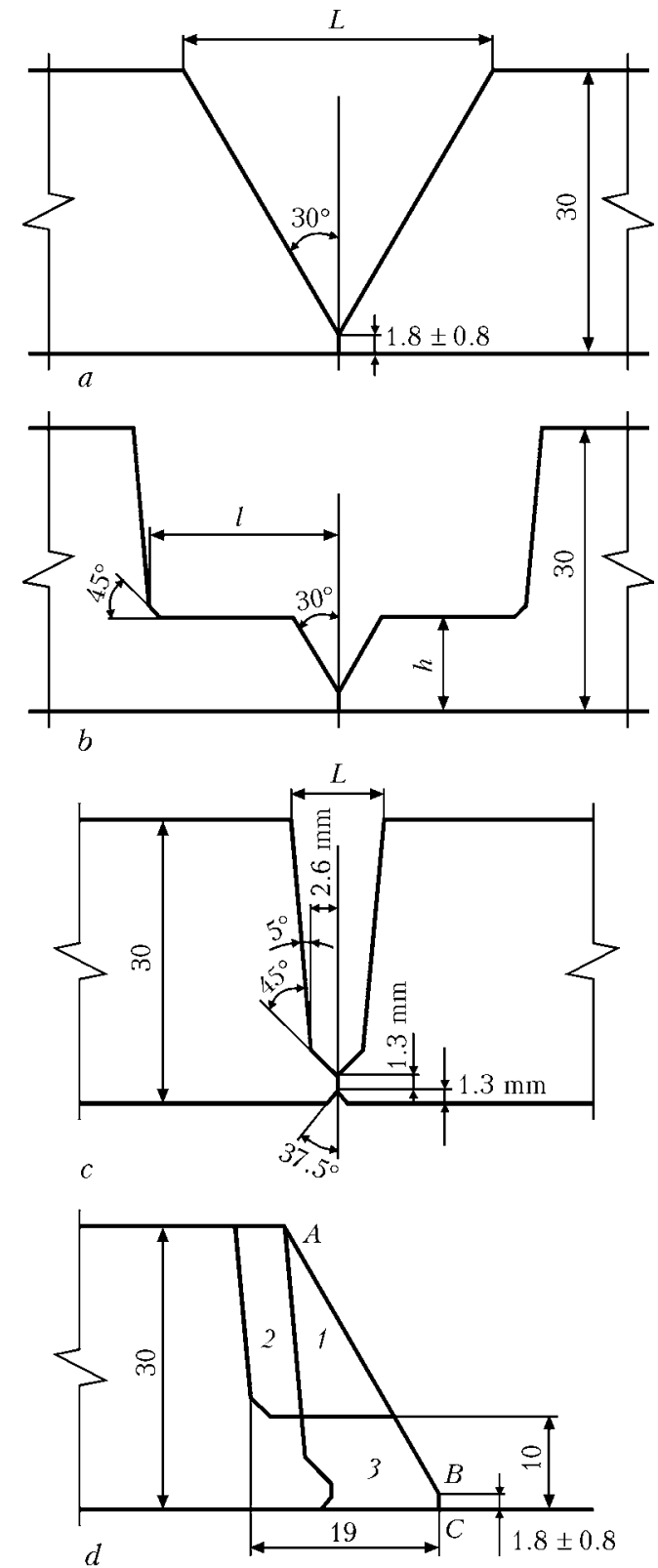

Figure 1. Schemes of edge preparation for manual EAW $(a)$, FBW $(b)$, CRC method $(c)$ and combined schemes $(d)$ (for designations see the text)

The parameters of edge groove for FBW of root welds of thick-walled pipes can vary within the wide ranges and significantly differ from the parameters of grooves of the known EAW methods. During welding of combined joints it allows minimizing the energy input during preparation and welding of pipes, improving the labor efficiency, reducing the consumption of welding consumables for EAW, the cost of which is $2-3$ times higher than that of pipe materials. The latter is particularly important in the construction of pipelines at the distant regions, where it is necessary to deliver a large volume of welding consumables for EAW.

The aim of this work is the development of technology for FBW of root welds during con- 
struction of pipelines with wall thickness of more than $20 \mathrm{~mm}$, as well as investigation of quality, determination of mechanical properties of root welds and combined joints.

The investigation of technology for welding of root welds was performed on the sectors of 100-200 mm width of pipes of $219 \times 20$ and $325 \times$ $\times 25 \mathrm{~mm}$ of carbon steel and thick-walled pipes of modern production of $1219 \times 27 \mathrm{~mm}$ of steel $10 \mathrm{G} 2 \mathrm{FB}$. For practicing the conditions for welding of root welds of 6-12 mm thickness the plates of carbon steel rolled metal of up to $30 \mathrm{~mm}$ thickness were used. Welding of sectors and plates was performed in the laboratory equipment with the program control of basic parameters of the condition [7]. For approbation of welding conditions the pipes of $219 \times 20 \mathrm{~mm}$ of steel $20 \mathrm{~T}$ were taken. The pipes were welded in machine K584 using the program, in which the basic parameters varied in the function of movement, that allowed performing the preset allowances for flashing and upsetting at the accuracy of $\pm 0.5 \mathrm{~mm}$.

The quality of the investigated butts was evaluated according to the results of mechanical tests conducted in accordance with the actual standards, as well as to the results of metallographic analysis of the joints and fractographic investigations of fractures of specimens specially fractured along the root weld.

For FBW of root weld the edge groove was carried out on pipe ends at the parameters of projections $h$ and $l$ as is shown in Figure 1,b. The groove was prepared by reducing the pipe wall thickness on the side of the pipe outer surface. For this purpose the standard equipment is applied, i.e. the mobile edge beveling machines. After welding of projections the root weld is formed. The scheme of the root weld produced by FBW is shown in Figure 2, $a$. After producing the joint the reinforcement of the root weld and overlaps of metal must be removed and the remaining part of the groove must be filled by EAW.

While determining the geometric sizes of edge groove for FBW of pipes it should be taken into account that with decrease in thickness of the projections the volume of mechanical treatment of edges increases, as well as the volume of groove for its filling by EAW.

In Figure $1, d$ the scheme for comparison of grooves for pipes with wall thickness of $30 \mathrm{~mm}$ for combined welding technologies is presented. As the analogue for comparison the following grooves were chosen: factory groove, marked by the contour $A-B-C$ (see Figure $1, d$ ) and groove, prepared according to the CRC technology (see
Figure 1,c). The parts of the edges, removable during different welding methods, are marked as 1,2 and 3. For FBW of root welds with $h=$ =6-7 $\mathrm{mm}$, region 1 is removed, and in welding at $h>7 \mathrm{~mm}$ region $1+2$ is removed. In CRC, respectively, region $1+3$ is removed. From the comparison of regions 2 and 3 it is seen that region 2 by its area is approximately equal to region 3. Therefore, the labor intensity of edge preparation in FBW does not exceed the volume of CRC works.

In the process of investigations the parameters of the groove were changed in the range of $h=$ $=6-12 \mathrm{~mm}$ and $l=10-22 \mathrm{~mm}$. Moreover, in all the cases the width of edge preparation $L$ (see Figure 2,a) along the outer surface of pipes remained equal to the specified size for producing the filling weld by EAW.

In FBW the projections of groove are shortened to the size of allowance for welding: $\Delta_{\mathrm{w}}=$ $=\Delta_{\mathrm{fl}}+\Delta_{\mathrm{ups}}\left(\Delta_{\mathrm{fl}}\right.$ and $\Delta_{\mathrm{ups}}-$ allowances for flashing and upsetting, respectively). Choosing the groove parameter value $l$ not only the allowance for welding should be taken into account, but also the features of FB-welded joint formation, when the reinforcement is formed between the edges of groove during upsetting on the root weld surface.

In Figure 2, $a$ the scheme of the joint is presented produced at the optimum correlation of the mentioned parameters considering the size of reinforcement. In case of violation of this requirement, the compression of reinforcement occurs with overlaps of the oxidized metal by edges of the groove. After removal of the upper part of reinforcement with overlaps of metal, especially during visual evaluation of cleaning of welded joint and the readiness of groove for filling by EAW, a false impression of complete removal of the reinforcement may appear. In fact, between the edges of groove and the remaining part of reinforcement the clamped interlayers of oxidized metal appear, which are difficult to remelt by EAW, when filling the groove.

The macrostructure of combined joint with the interlayers of oxidized metal at the root weld is presented in Figure 2, c. In order to guarantee the formation of a high-quality joint without such defect between the reinforcement and the edges of groove the technological gap $k$ should be provided (see Figure 2, $a$ ).

It was experimentally established that in welding of root welds with groove parameter $h=$ $=6-12 \mathrm{~mm}$ the technological gap $k$ should be 1.5-2 mm. Thus, parameter $l$ of groove before FBW of thick-walled pipes with wall thickness 

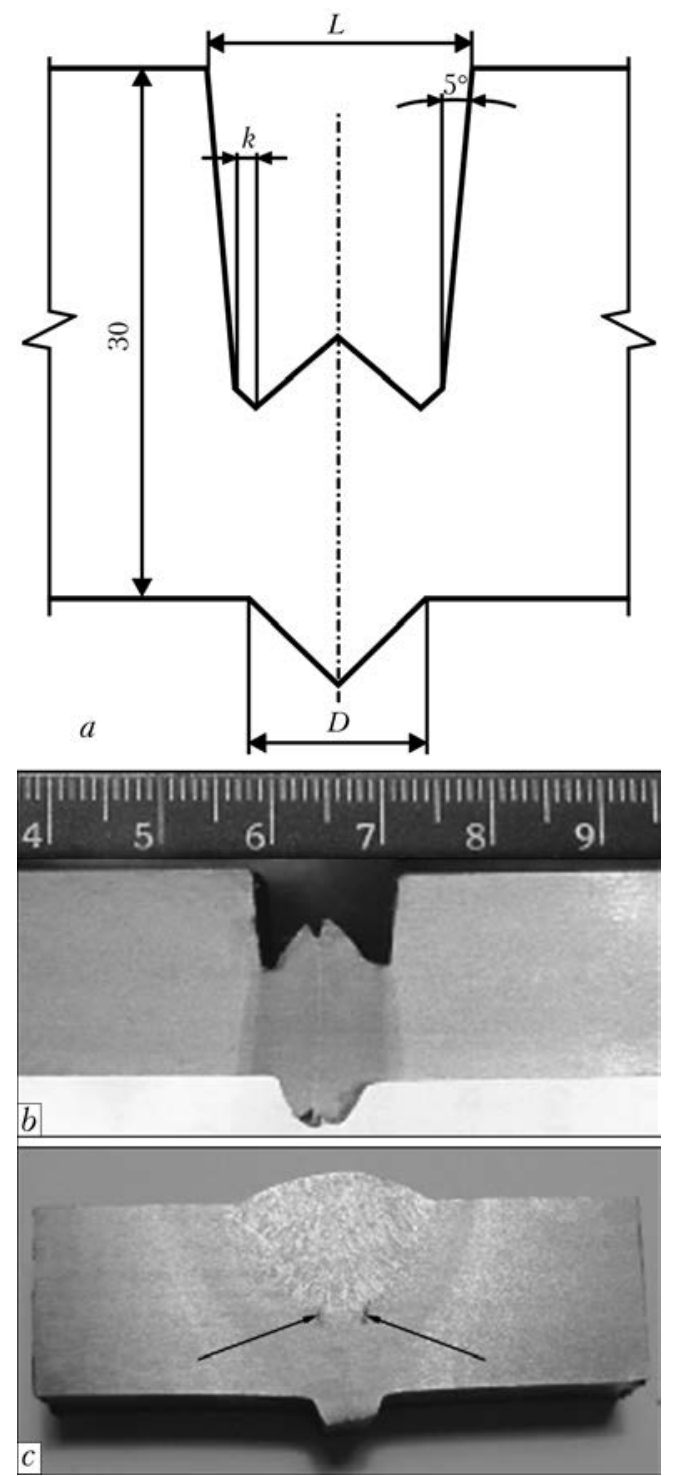

Figure 2. Scheme of root weld produced at optimal FBW conditions ( $a-$ for designations see the text), macrosection of root weld $(b)$, and macrosection of combined joint during violation of welding mode parameters $(c-$ arrows indicate lack-of-fusion of weld metal)

$\delta>20 \mathrm{~mm}$ is determined by the following dependence: $l=\Delta_{\mathrm{w}} / 2+D / 2+k$ (where $D$ is the width of root weld reinforcement). Since our investigations established that $D / 2+k \sim h / 2$, parameter of the groove projections is $l=\Delta_{\mathrm{w}} / 2+$ $+h / 2$ (where $h$ is the thickness of projection in the groove edges).

In determination of optimal conditions of FBW of pipes with different parameters of edge preparation it is necessary, first of all, to take into account the complex effect of thickness of projections $h$ on the basic values of flashing process. As is seen from the diagram of Figure 3, $a$, with the increase of $h$ parameter the duration of welding process and allowance for flashing are increased, and the specific power consumption is decreased. In welding of thick-walled pipes with
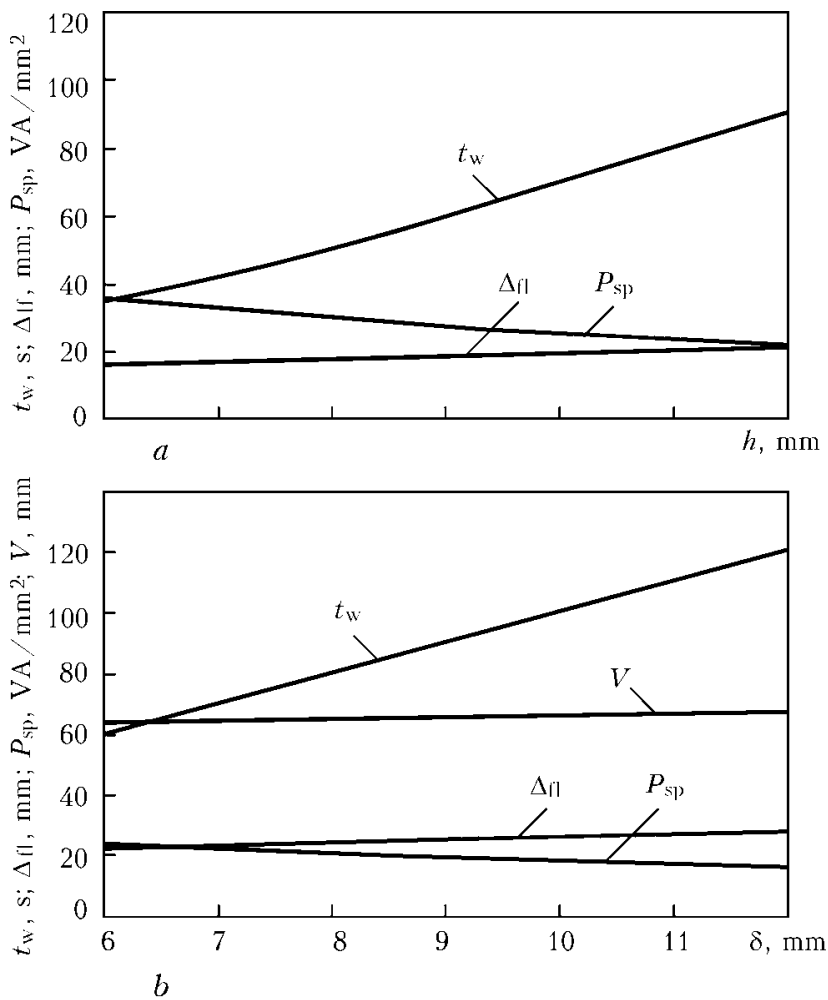

Figure 3. Dependence of duration of welding process, allowance for flashing, specific power in final period of flashing and value of extension from current-carrying clamps on thickness of projections $(a)$ and pipe wall thickness $(b)$

edge preparation at the identical conditions the formation of joint will occur under the conditions of more intensive heat removal from the welding zone to the body of thick-walled pipe. The configuration of pipe edges with the groove creates heating conditions, which occur during welding of pipes with reduced extensions. In the first case, heat is removed into the massive volumes of metal, and in the second case - into the current-carrying clamps.

Figure 4 shows the dependence of amount of heat accumulated in the heating zone on the value of extensions from the clamps of the welding machine during flashing of sectors of pipes with $\delta=10 \mathrm{~mm}$, obtained by the calorimetry of the flashed specimens. The 3.5 times shortening of the extensions of sectors in welding resulted in 45-50\% increase in energy losses. The presented data relate to the heating conditions in flashing of sectors, when heat removal into the clamps occurs on both sides. These losses are lower during one-sided heat removal in welding of pipes, but they can significantly influence the formation of joints at minimum distances from clamps to welding zone.

The data, given in Figure 3, $b$, corresponds to the conditions of FBW of pipes with $\delta=6-12 \mathrm{~mm}$ in machines K584. For example, during welding of $10 \mathrm{~mm}$ pipes without grooving, as is seen from 


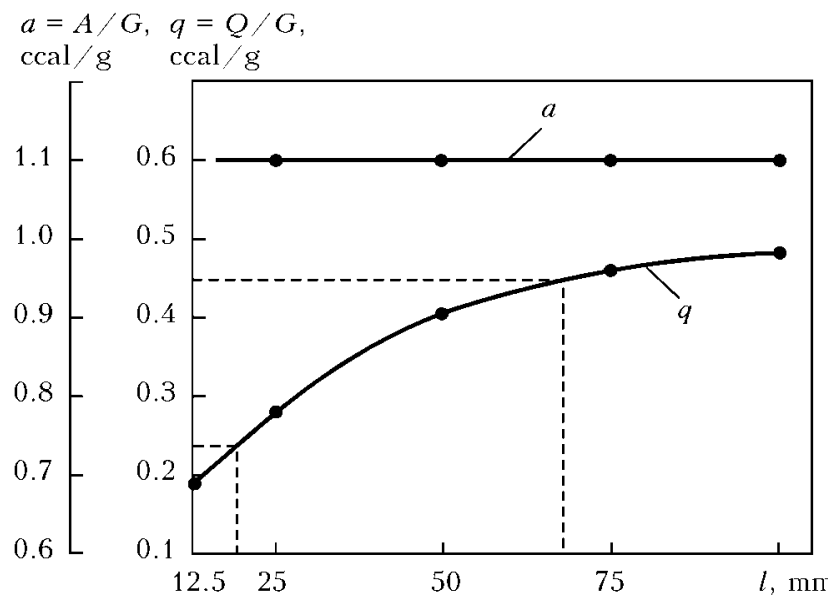

Figure 4. Dependence of specific volume of saved $q$ and consumed $a$ power on size of extensions in welding of sectors $10 \mathrm{~mm}$ thick

the diagram, the value of extensions from the clamps must be at least $68 \mathrm{~mm}$, which is 3.5 times larger than length $l$ of groove projections at $h=$ $=10 \mathrm{~mm}$.

Figure 5 (curve 1) shows distribution of temperature at the area of $12 \mathrm{~mm}$ length from the flashing surface during welding of pipes of $219 \mathrm{~mm}$ diameter with $\delta=10 \mathrm{~mm}$ at the standard conditions (distance between the current-carrying clamps is $68 \mathrm{~mm}, t_{\mathrm{w}}=95 \mathrm{~s}$ ), providing the quality welding.

Curve 2 in Figure 5 characterizes the distribution of temperature in the same HAZ area of specimens of thick-walled pipes with $\delta>20 \mathrm{~mm}$, $h=10 \mathrm{~mm}$ and $l=19 \mathrm{~mm}$. The temperature at the investigated area is lower than $100-150{ }^{\circ} \mathrm{C}$. At the bend tests of standard specimens of these joints the values were not stable. Some specimens encountered cracks along the joining zone.

The losses for heat removal can be compensated to some extent by increasing the intensity of heat source during flashing in its different periods envisaged by the program.

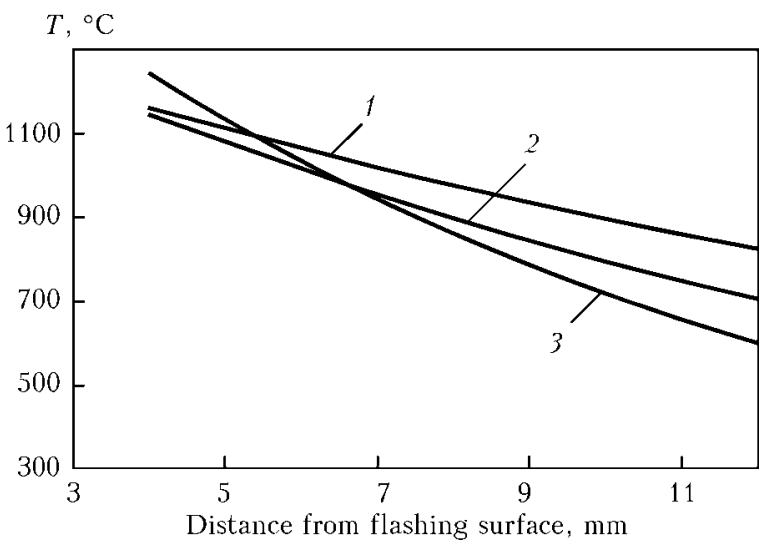

Figure 5. Linear distribution of temperature in welding of $219 \times 10 \mathrm{~mm}$ pipes at regulated conditions (1), of root weld with $h=10 \mathrm{~mm}$ of $219 \times 10 \mathrm{~mm}$ pipe at regulated (2) and optimal (3) condition
The more severe welding conditions for all the investigated thicknesses of the projections result also in increase of the specific pressures required for producing the quality joints. Therefore, when designing the specialized equipment for combined welding one can not expect a significant reduction in its power and weight, at least for the accepted correlation of sizes of the groove projections. With $l$ increase the conditions of welding of pipes will approach the accepted ones for the corresponding wall thicknesses without edge preparation, and the reduction in power values will be more noticeable.

It should be noted that at the optimization of the groove shape for combined welding the power values of the equipment are not dominant. The reduction of time for welding the root weld to 1-2 min regardless of diameter of the pipes allows improving the efficiency of general technological flow at the construction of pipelines.

In determination of the optimum $h$ value the tolerance of the accepted technology for the accuracy of pipes assembly before welding is a very important characteristic. With increase in thickness of groove projections the displacement of edges and the gap between them influence the quality of the joints to a lesser extent, and the admissible deviations may be wider. From this point of view the thicknesses of projections within the range of $8-12 \mathrm{~mm}$ appear to be the most acceptable.

As the result of carried out investigations the conditions of welding of thick-walled pipes of $219 \mathrm{~mm}$ diameter with $\delta=20 \mathrm{~mm}$ with edge preparation in machine K584 were developed. The thickness of groove projections varied in the range of $6-12 \mathrm{~mm}$, and the size $L$ of groove remained unchanged and equal to the preset value. The diagrams in Figure 3, $a$ show the optimal values of basic parameters at rigid conditions, providing the quality joints with different thickness of the projections. The optimal mode is characterized by an increased specific power (30 \%), shorter time of welding (by 20-40\%) and lower allowance for welding (by 20-30\%) than the recommended one for the pipes with the same wall thicknesses. Such joints are characterized by narrow HAZ, the size of which does not exceed parameter $l$. The macrosection of such joint with $h=10 \mathrm{~mm}$ is shown in Figure 2, b.

The temperature distribution in the heating zone during welding of root welds $10 \mathrm{~mm}$ thick at such conditions is shown in Figure 5 (curve 3 ). The comparison of curves 2 and 3 shows that increase in concentration of heating by increasing the power at all the welding stages allowed re- 
ceiving the temperature distribution in the contact areas required for formation of the quality joints.

The comprehensive mechanical tests of root welds of all the investigated thicknesses, carried out at optimal conditions, confirmed the high quality of joints.

The joints of root welds of low-alloy steel of strength group X70, produced at the optimum conditions, showed high and stable results. The specimens for rupture were fractured along the root, comprising in general the whole welding zone (Figure 6, $a$ ). Rupture stresses remained within the ranges of $\sigma_{\mathrm{r}}=640-657 \mathrm{MPa}$, which is higher than tensile strength of the metal of pipes $\left(\sigma_{t}^{p}=610 \mathrm{MPa}\right)$. This is explained by the fact that plastic deformation is concentrated in the narrow zone of root weld with small crosssection, which leads to mechanical hardening of metal of all the areas of the root.

After fracture the specimens had breaks, which are defined as tough ones, proving the ductility of the weld root. These data are confirmed by the bending tests of root welds. Due to the small extension of deformable area (of root weld), located in the edge grooves, high stresses occur in the metal. Despite such severe tests the specimens had bending angle of $180^{\circ}$ without cracks in welding zone (Figure $6, b$ ). Strength of root welds on pipes of steel 20 was $\sigma_{\mathrm{r}}=534-$ $559 \mathrm{MPa}$, and $\sigma_{\mathrm{t}}^{\mathrm{p}}=518 \mathrm{MPa}$.

The fracture surfaces of the root welds during the rupture tests had a developed homogeneous relief without defects of welding.

The next stage of the carried out investigations was the study of properties of the combined joints, produced by filling the groove formed as a result of manual EAW of root weld of the groove. Before deposition the reinforcement and metal overlaps of FB-welded joint were removed in the grooves.

Deposition was carried out using electrodes UONI-45/55 under the conditions recommended for welding of steel products. All the joints showed high properties that meet the requirements of standard documents [3, 8]. Figure 7 shows macrosection and specimens after rupture and bending tests. Strength and ductility of joints corresponds to the values of pipes metal. The rupture specimens were fractured beyond the welding zone along the pipes metal. The bent specimens at $180^{\circ}$ angles had no cracks.

During filling the grooves by EAW the root weld metal undergoes thermal effect, which by its nature is manifested itself as heat treatment. The measurements of metal temperature in con-

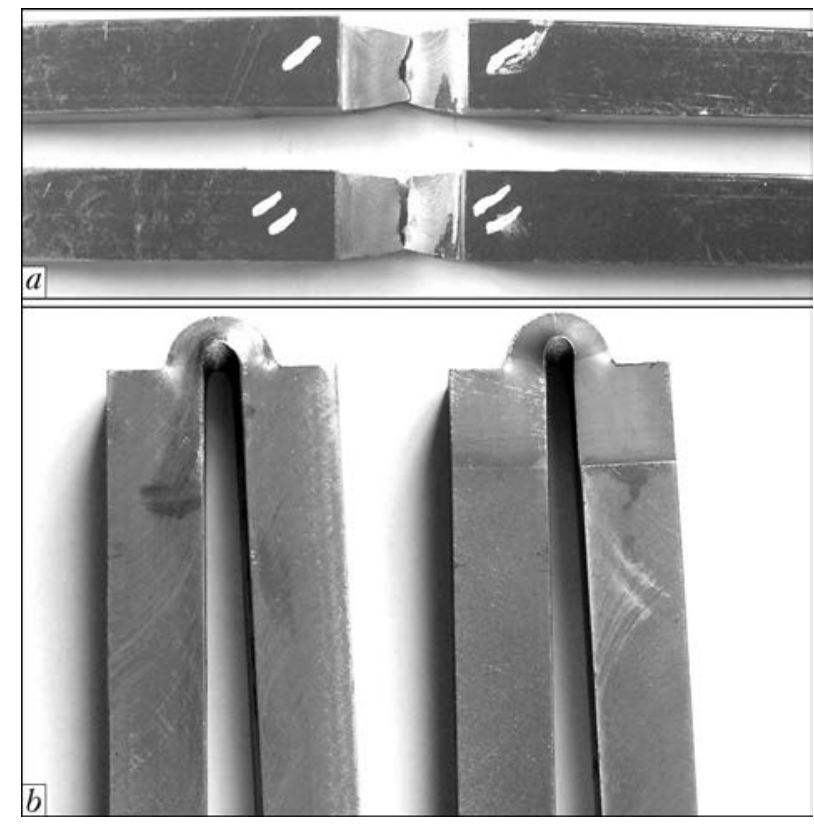

Figure 6. Specimens of steel 10G2FB joints with root weld after tensile $(a)$ and bend $(b)$ test

trol spots along the weld on the side of surface under the grooves showed that its values at the elementary area at different EAW conditions may vary within the range from 600 to $1150{ }^{\circ} \mathrm{C}$.

The efficiency of thermal effect of different EAW conditions on properties of the combined joints was evaluated according to the values of impact toughness. $K C V$ was determined on the standard specimens with a sharp notch, produced across the wall thickness. The proportion of FBwelded joints was 30-50\%. Such specimens determine to the greatest extent the ductile properties of joints with different state of the combined weld metal, one part of which was produced by FBW without ast metal, and another one - by EAW with cast metal.

The results of investigations showed a significant effect of EAW thermal cycle on the metal of root welds at the temperatures higher critical point $A_{c 3}$, i.e. at normalization temperatures. This method of heat treatment is recommended to improve the values of impact toughness of FB-welded joints [9, 10].

In deposition of $10 \mathrm{~mm}$ root weld the duration of staying the metal at $900-1150{ }^{\circ} \mathrm{C}$ at the certain areas of the weld regardless of its thickness was in the range of 20-30 s. As a result of this scattering of thermal effect parameters between the maximum and minimum values of impact toughness at the same weld a great difference is observed. Impact toughness of specimens of steel 20 joints was as follows, $\mathrm{J} / \mathrm{cm}^{2}$ : at $+20{ }^{\circ} \mathrm{C}-(62-$ 142) $/ 83$, at $-20{ }^{\circ} \mathrm{C}-(20-51) / 39$, for metal of pipes of steel 20 at $-20{ }^{\circ} \mathrm{C}$ it was $(23-49) / 40$. The joints of pipe steel 10G2FB showed impact 

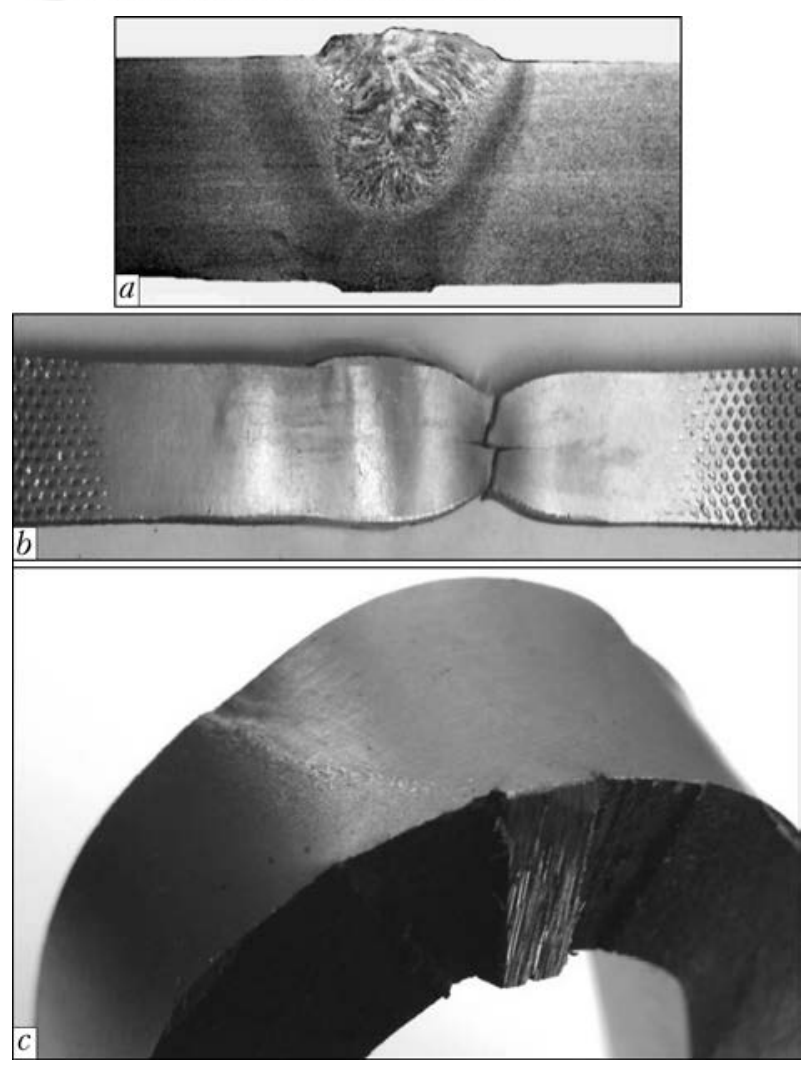

Figure 7. Macrosection ( $a$ ) of specimen of combined joint and its appearance after rupture $(b)$ and bend $(c)$ test

toughness at $+20{ }^{\circ} \mathrm{C}$ it was $(96-206) / 114$, and at $-20{ }^{\circ} \mathrm{C}(20-49) / 42 \mathrm{~J} / \mathrm{cm}^{2}$. At the negative temperature the individual specimens appear, which have the values lower than the minimum required ones. However, they do not negatively affect the operational properties of welded joints of pipes of the full cross-section. This is proved by the results of the presented studies [11, 12].

Thermal effect of EAW is increased with the increase in duration of staying the metal at the normalization temperatures by deposition of subsequent hot layers on the first deposited layer. In this case the root weld metal undergoes cyclic thermal effect (Figure 8). For example, in manual EAW the time of staying the elementary weld area at the normalization temperatures for the first cycle amounted to $20 \mathrm{~s}$. The total time of two cycles amounted to $45 \mathrm{~s}$, and at the account for the third cycle the time increased up to $80 \mathrm{~s}$. As a result, the average values of impact toughness increased by $8-14 \%$. At the same time, between the first-second and the second-third cycles there were technical breaks (for slag removal) of $90 \mathrm{~s}$ duration. The joints of steel X70 had 46$48 \mathrm{~J} / \mathrm{cm}^{2}$ impact toughness at $-20{ }^{\circ} \mathrm{C}$.

In the combined joints with root $12 \mathrm{~mm}$ thick the length of areas, not subjected to thermal effect, increases. As a result, the number of specimens with minimal values is increased.

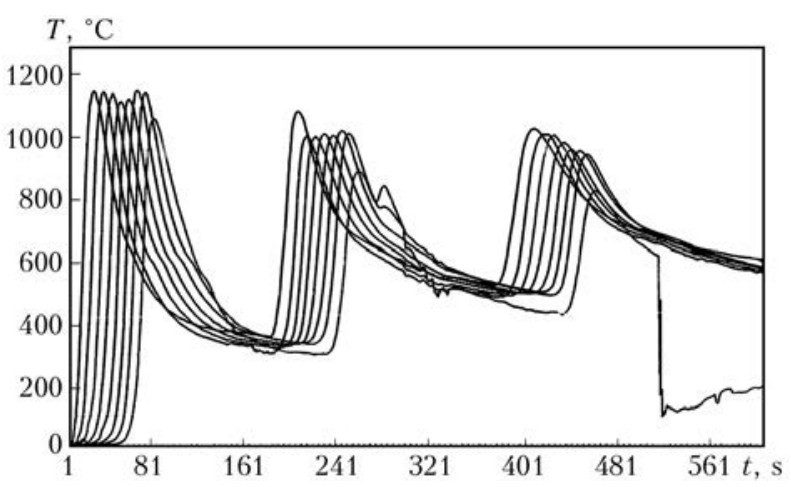

Figure 8. Temperature distribution in weld root during filling the groove by EAW

For manual EAW the non-uniformity of heat effect is characteristic. It can be judged by penetration depth of the root weld. At the area of $120 \mathrm{~mm}$ length at $10 \mathrm{~mm}$ root the penetration was in the range of $0.2-3.0 \mathrm{~mm}$.

It should be noted that a great difference between the minimum and maximum values of the individual specimens can be caused not only by the non-uniform heat effect on the root weld metal, but also by the objectively existing properties of impact tests of welded joints, regardless of their welding method, when in many cases the scattering of values occurs $[13,14]$.

The combination of flash-butt and electric-arc welds provides mutual positive effect on the properties of the joints. On the one hand, there is no cast metal in the flash-butt weld and, respectively, a number of defects peculiar to EAW is absent in it. At the same time, under the influence of EAW the root weld is subjected to heat treatment. Sometimes it turns to be insufficiently complete at the negative testing temperatures, but in any case it promotes the improvement of ductile properties of the welded joint metal.

\section{Conclusions}

The basic technology for FBW of thickened root welds of position butts of thick-walled pipes of 219-325 mm diameter with wall thickness of more than $20 \mathrm{~mm}$ of carbon and high-strength steels was developed, and the optimum geometric sizes of edge preparation and optimum parameters of FBW of root welds of thick-walled pipes were determined.

The comprehensive mechanical tests of root welds and combined joints were carried out proving their equal strength with the pipe metal.

The positive effect of heat input on ductile properties of the root weld metal, produced by FBW, during filling the groove of weld by EAW was established. 
The power characteristics of the equipment, required for FBW of root welds 6-12 mm thick, by using the existing park of machines for FBW of pipes were determined.

1. Vyshemirsky, E.M., Bespalov, V.I., Budrevich, D.G. et al. (2009) Definition of technical requirements to welded joints of gas pipelines from high-strength steels applicable to main Bovanenkovo-Ukhta pipeline. In: Proc. of 3rd Int. Sci.-Techn. Conf. on GasTransport Systems: Present and Future (27-28 Oct. 2009), 312-321.

2. Kozlov, V.V. (2010) Organizing and activities on quality assurance of welding operations in construction of main Sakhalin-Khabarovsk-Vladivostok pipeline. In: Proc. of branch meeting of OAO Gazprom (Moscow, 15-19 Nov., 2010), 108-112.

3. STO Gazprom: Instruction on welding of main pipelines with service pressure up to $9.8 \mathrm{MPa}$. Introd. 22.09.2007.

4. Paton, B.E., Lebedev, V.K., Kuchuk-Yatsenko, S.I (1979) Complex «Sever-1» for flash-butt welding of position joints of large diameter pipes. Avtomatich. Svarka, 11, 41-45.

5. Mazur, I.I., Serafin, O.M., Karpenko, M.P. (1989) Flash-butt welding of pipelines: Ways of improvement. Stroitelstvo Truboprovodov, 4, 8-11.

6. Khomenko, V.I., Kuchuk-Yatsenko, S.I., Kazymov, B.I. et al. Method of welding of pipes in construction of pipelines. Pat. 222998 RF. Publ. 27.02.2003.
7. Kuchuk-Yatsenko, S.I. (1992) Flash-butt welding. Kiev: Naukova Dumka.

8. API Standard 1104 (1999) Welding of pipelines and related facilities ASME boiler and pressure vessel. 19 ed.

9. Kuchuk-Yatsenko, S.I. Pismenny, A.S., Shinlov, M.E. et al. (2006) Accelerated induction heat treatment of pipe welds from controlled-rolled steels. The Paton Welding J., 3, 7-10.

10. Kuchuk-Yatsenko, S.I., Shvets, Yu.V., Zagadarchuk, V.F. et al. (2013) Technology of heat treatment of pipe joints from steel of K56 grade produced by flashbutt welding. Ibid., 2, 2-7.

11. Kuchuk-Yatsenko, S.I., Kirian, V.I., Kazymov, B.I. et al. (2008) Peculiarities of impact toughness tests of automatic flash butt welded joints on pipes. Ibid., 10, 5-10.

12. Kirian, V.I., Kuchuk-Yatsenko, S.I., Kazymov, B.I. (2015) Concerning requirements to impact toughness of joints of pipelines produced using flash butt welding. Ibid., 2, 2-6.

13. Kirian, V.I., Semenov, S.E. (1995) Evaluation of fitness for purpose of welded joints of main pipelines from microalloyed steels. Avtomatich. Svarka, 3, 4-9.

14. Kuchuk-Yatsenko, S.I., Kirian, V.I., Kazymov, B.I. et al. (2006) Methodology for control of fitness for purpose of flash butt welded joints in pipelines. The Paton Welding J., 10, 2-6.

Received 01.07.2015 